\title{
Angiogenic pretreatment improves the efficacy of cellular cardiomyoplasty performed with fetal cardiomyocyte implantation
}

\author{
Mauricio A. Retuerto, BS \\ Paul Schalch, MD \\ Gerald Patejunas, $\mathrm{PhD}^{\mathrm{a}}$ \\ JoAnn Carbray, BS ${ }^{\mathrm{a}}$ \\ Naxin Liu, MD \\ Karyn Esser, $\mathrm{PhD}^{\mathrm{c}}$ \\ Ronald G. Crystal, $\mathrm{MD}^{\mathrm{d}}$ \\ Todd K. Rosengart, MD ${ }^{a, b}$
}

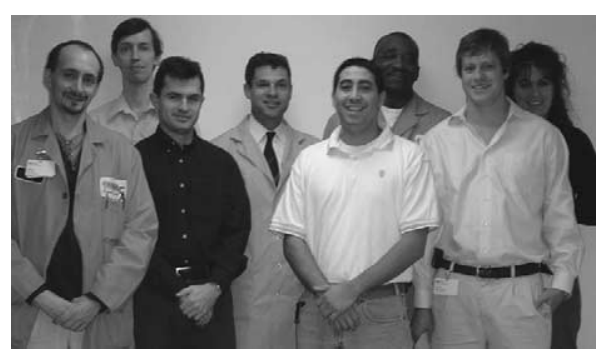

Background: Cell implantation into areas of myocardial infarction (cellular cardiomyoplasty) may be limited in efficacy because of the lack of blood supply to these areas of myocardium, resulting in early loss of transplanted cells. We therefore tested the hypothesis that pretreatment of infarcted myocardium with angiogenic therapy, followed by cell transplant, would be more effective than the application of either strategy alone.

Methods: Fischer 344 rats underwent left coronary artery ligation and injection of an adenovirus encoding VEGF 121, an empty expression cassette control vector, or saline solution. Capillary density in the infarcted region was determined in preliminary studies. Cardiomyocytes harvested from syngeneic Fischer rat fetuses were prelabeled and then injected directly into the infarct area 3 weeks after vector administration. Exercise treadmill testing was performed 2

From Evanston Northwestern Healthcare, ${ }^{\mathrm{a}}$ Evanston, Ill; Feinberg School of Medicine of Northwestern University, ${ }^{\text {b }}$ Chicago, Ill; University of Illinois at Chicago, ${ }^{\mathrm{c}}$ Chicago, Ill; and Weill Medical College of Cornell University, ${ }^{\mathrm{d}}$ New York, NY.

Supported in part by the National Institutes of Health/National Heart, Lung, and Blood Institute (R01HL66981, R01HL57318, and R01HL61719), Evanston Northwestern Healthcare Women's Auxiliary Fund (Evanston, Ill), and GenVec, Inc (Rockville, Md).

Read at the Twenty-ninth Annual Meeting of The Western Thoracic Surgical Association, Carlsbad, Calif, June 18-21, 2003.

Received for publication May 22, 2003; revisions requested Sept 5, 2003; accepted for publication Sept 18, 2003.

Address for reprints: Todd K. Rosengart, MD, 2650 Ridge Ave, Burch 100, Evanston, IL 60201 (E-mail: trosengart@enh. org).

J Thorac Cardiovasc Surg 2004;127: 1041-50

$0022-5223 / \$ 30.00$

Copyright (C) 2004 by The American Association for Thoracic Surgery

doi:10.1016/j.jtcvs.2003.09.049 weeks after cell transplantation, after which a cell viability index was calculated as the number of implanted (prelabeled) nuclei divided by the number of coadministered microspheres detected in sections of implanted myocardium.

Results: Capillary density in the area of infarction was significantly greater in adenovirus encoding VEGF 121 compared with rats injected with saline solution $(P=.001)$. The cell survival index was also greater in adenovirus encoding VEGF 121 compared with animals injected with empty expression cassette control or saline solution $(P=.0045)$. Exercise tolerance was nearly doubled in animals receiving adenovirus encoding VEGF 1213 weeks prior to cell implantation compared with animals receiving adenovirus encoding VEGF 121 or cells alone or those receiving adenovirus encoding VEGF 121 at the time of cell implantation $(P<.001)$.

Conclusions: Pretreatment of an infarcted region of the heart with angiogenic mediators such as VEGF can enhance the efficacy of cellular cardiomyoplasty, presumably by creating a more favorable environment for the survival of transplanted cells.

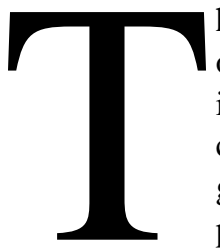

herapeutic angiogenesis describes the strategy wherein naturally occurring growth factors or progenitor cells are administered to ischemic tissues to induce the formation of new blood vessels that can restore perfusion to ischemic tissues. ${ }^{1,2}$ The potential for angiogenic therapy to restore ventricular function is predicated upon the presence of a substrate of contractile, or at least hibernating, cardiomyocytes. In contrast, reperfusion of scarred, infarcted myocardium is unlikely to 
enhance myocardial function because of the relative absence of viable myocytes in this tissue. In such circumstances, it has been demonstrated in numerous animal studies that cellular cardiomyoplasty, wherein reserve cells such as skeletal myoblasts, fetal cardiomyocytes, embryonic stem cells, or bone marrow stem cells are implanted into myocardial scar, can arrest or reverse ventricular remodeling and improve myocardial function. ${ }^{3-13}$ In this therapy, the implanted cells, which are typically harvested autogenously and expanded in culture, essentially "repopulate" the area of nonfunctioning myocardial scar with viable myocytes. Based on these findings, several dozen individuals have now undergone cellular cardiomyoplasty in phase I clinical trials. ${ }^{14,15}$

Despite these encouraging initial results, it appears that a great number of cells do not survive implantation into areas of infarcted myocardium. ${ }^{16-18}$ This loss of cells is not unexpected given the unresolved ischemia in the area of infarction into which the reserve cells are typically implanted. ${ }^{16-18}$ Under such conditions, implanted cells would theoretically undergo necrosis or apoptosis and replacement by fibroblasts and scar, similar to the fate of the cells originally occupying the same ischemic territory. Possibly on this basis, improvements in ventricular performance noted in cellular cardiomyoplasty studies have thus far been somewhat modest, on the order of $10 \%$ to $30 \%$. $^{3-13}$

We hypothesized that cell loss could be limited and the results of cellular cardiomyoplasty improved by pretreating the area of infarction with angiogenic therapy to improve the perfusion to this scar tissue prior to cell implantation. Accordingly, we demonstrated that angiogenic pretreatment of scar tissue 3 weeks prior to syngeneic fetal cardiomyocyte implantation in a rat coronary ligation model enhances vascularization of the scar, improves the viability of subsequently implanted cells, and enhances functional improvement of animals compared with results following cell therapy alone.

\section{Methods}

\section{Model Preparation and Vector Administration}

Adult male Fischer 344 rats (275-300 g; Harlan; Indianapolis, Ind) were treated in accordance with protocols approved by our Institutional Animal Care and Use Committee. The animals were anesthetized with intraperitoneal ketamine/xylazine $(85 / 12 \mathrm{mg} / \mathrm{kg}$ body weight), intubated, and placed on a rodent ventilator (Harvard Apparatus, Holliston, Mass). A left thoracotomy was then performed in the fourth intercostal space, and the left coronary artery was identified and ligated 1 to $2 \mathrm{~mm}$ from its origin using a 7-0 polypropylene suture. At this time, 5 uniformly distributed $20-\mu \mathrm{L}$ injections each containing $2.0 \times 10^{9} \mathrm{pu}\left(1.0 \times 10^{10}\right.$ total dose) of replication defective adenovirus encoding for the 121 amino acid isoform of vascular endothelial growth factor (AdVEGF), an adenovirus with an empty expression cassette (AdNull) prepared as previously described, ${ }^{19,20}$ or an equal volume of phosphate-buffered saline solution (PBS) were administered into the infarct zone. The thoracotomy was then closed in layers, and the animal was allowed to recover under supervision. Buprenex was administered subcutaneously ( $0.65 \mathrm{mg} / \mathrm{kg}$ body weight) shortly after extubation to provide analgesia.

\section{Immunohistochemical Analysis of Vascularization}

In preliminary experiments, myocardial histologic analysis was performed 3 weeks after animals underwent coronary ligation and myocardial injection of AdVEGF or PBS ( $n=6 /$ group). The animals were killed with a pentobarbital overdose; the hearts were excised and fixed using zinc-formalin prior to paraffin embedding. Sections taken at $100-\mu \mathrm{m}$ intervals with a $5-\mu \mathrm{m}$ thickness were prepared for immunohistochemistry utilizing a fluorescein-labeled lectin (Galanthus Nivalis lectin, Vector Laboratories, Burlingame, Calif). The sections were then analyzed at $200 \times$ in a blinded manner using Metamorph Software (Universal Imaging, Downingtown, $\mathrm{Pa}$ ), and capillary density was calculated for each animal from 2 fields randomly selected from each of 5 sections of infarcted myocardium.

\section{Isolation of Fetal Cardiomyocytes}

Gestation day 20 fetuses were harvested from syngeneic Fischer 344 rats, and their hearts were excised, washed in cold ethanol, and stored in cold Ack Lysing Buffer (BioSource International, Camarillo, Calif). The hearts were then minced and cardiomyocytes were isolated as previously described. ${ }^{18}$ Cardiomyocyte isolation was verified by detection of cell contractions 24 hours after initial plating. Harvested cells were expanded in Dulbecco's modified Eagle's medium-F12 media with 10\% fetal bovine serum, insulintransferrin-selenium, and penicillin-streptomycin (Gibco BRL, Grand Island, $\mathrm{NY})$ at $37^{\circ} \mathrm{C}\left(5 \% \mathrm{CO}_{2}\right)$ for no more than 10 days, or until they were $90 \%$ confluent. $^{18}$

\section{Fetal Cardiomyocyte Preparation}

Fetal cardiomyocytes expanded in culture as described above were suspended using trypsin $0.025 \%$ /ethylenediaminetetraacetic acid (Gibco BRL), and then collected in PBS. The cells were then treated with a $1-\mu \mathrm{mol}$ solution of Hoechst 33342 (Sigma, St Louis, $\mathrm{Mo}$ ), a blue fluorescent DNA intercalator, and incubated at $37^{\circ} \mathrm{C}$ in $5 \% \mathrm{CO}_{2}$ for 15 minutes. The cells were subjected to 3 washes with $5 \times$ the initial media volume and then allowed to recover for 45 minutes in growth media. The cells were then collected and centrifuged, and aliquots of $1.5 \times 10^{6}$ cells were resuspended in 100 $\mu \mathrm{L}$ of PBS. An aliquot of $1 \times 10^{6}$ red fluorescent $2.0-\mu \mathrm{m}$ microspheres (Molecular Probes, Eugene, Ore), prepared according to manufacturer's specifications, was added to each fetal cardiomyocyte preparation as an internal standard for accuracy of myocardial delivery and sampling efficiency (final injectate cell:sphere ratio, 1.5:1). Prior to myocardial injection, a small sample was aspirated from the cell preparation and added to an equal volume of $0.4 \%$ trypan blue (Sigma), which was then assayed in a hemocytometer to determine cell viability.

In separate experiments, similarly prepared cells were heattreated $\left(65^{\circ} \mathrm{C}\right.$ for 15 minutes) or treated at $37^{\circ} \mathrm{C}$ for 15 minutes with $100 \mu \mathrm{mol} / \mathrm{L}$ of the apoptotic agent valinomycin (Sigma), according to manufacturer's specifications, to verify that the detection of nuclear staining could not be attributed to the staining of nonviable cells. These cells were first demonstrated to be nonvi- 


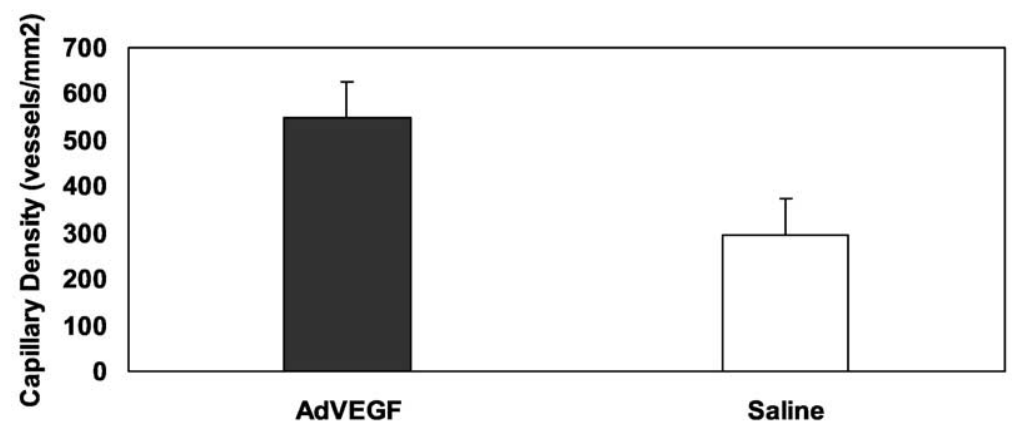

Figure 1. Vessel number (mean \pm standard deviation) in sections of infarcted myocardium obtained 3 weeks following the direct myocardial injection of AdVEGF or saline solution at the time of coronary ligation ( $n=6$ per group).

able utilizing flow cytometry analysis of an aliquot of cells labeled with a vital dye (LIVE/DEAD Viability Kit, Molecular Probes), according to the manufacturer's specifications (data not shown). Similarly treated cells were then administered into normal hearts utilizing the injection technique described below.

\section{Fetal Cardiomyocyte Administration}

A second left lateral thoracotomy was performed 3 weeks after the initial coronary ligation and vector administration. The region of myocardial infarction was identified as a grayish-white area on the anterolateral surface of the left ventricle (occupying approximately $20 \%-30 \%$ of the entire left ventricle). Five equidistant $20-\mu \mathrm{L}$ injections of PBS or the cell mixtures described above were then delivered subepicardially throughout the infarcted myocardium. In an additional set of animals that initially received PBS at the time of coronary ligation, both AdVEGF and cells were administered at the time of second thoracotomy. The chest was then closed and postoperative care was performed as described for the first operation.

\section{Exercise Tolerance Testing}

All animals were trained prior to the time of initial operation by running for 10 minutes at a constant speed of $15 \mathrm{~m} / \mathrm{min}$ on a multitrack small-animal motorized treadmill (Model 42-15, Quinton, Bothell, Wash). Immediately prior to the second operation (and cell implantation) and again 2 weeks later, the animals were exercised to the point of exhaustion (10 falls/min) on the same treadmill according to a standardized protocol, as follows: 10 $\mathrm{m} / \mathrm{min}$ for 5 minutes, $15 \mathrm{~m} / \mathrm{min}$ for 5 minutes, and $25 \mathrm{~m} / \mathrm{min}$ for the remainder of the treadmill protocol. ${ }^{21}$

\section{Cell Survival Analysis}

Immediately following the final exercise tolerance testing, all animals were anesthetized in an isofluorane chamber and killed using a lethal dose of pentobarbital. The hearts were then harvested, washed in saline solution, and fixed in zinc-formalin for 24 hours, as previously described. ${ }^{22}$ The ventricles were then cut into 3 equal transverse sections and prepared by frozen sectioning for analytical microscopy of unstained or hematoxylin and eosinstained serial sections. Fifteen cross sections of the infarcted region taken at $100-\mu \mathrm{m}$ intervals and a sectioning thickness of 7 $\mu \mathrm{m}$ were imaged using a Leica DMIRB microscope (Wetzler, Germany) and a Spot RT digital camera (Diagnostic Instrument Inc, Sterling Heights, Calif). Five fields per animal were analyzed in a blinded fashion at $400 \times$ with Metamorph Software using a red and blue fluorescence filter set (Chroma, Brattleboro, Vt). A cell survival index was calculated for each image as the ratio of total number of detected (fluorescent) nuclei divided by the total number of detected microspheres, and a mean cell survival ratio was calculated for each animal (AdVEGF: $n=9$; AdNull: $n=5$; PBS: $\mathrm{n}=7)$.

\section{Statistical Analysis}

Data are expressed as means and standard deviations. Analysis of variance was used to show significance; post-hoc tests with Bonferroni correction were used for pairwise comparisons.

\section{Results}

\section{Scar Angiogenesis}

The ability of angiogenic therapy to induce vascularization in areas of myocardial scar was analyzed in preliminary experiments. Vessel number was determined in sections of infarcted myocardium obtained 3 weeks following the direct myocardial injection of AdVEGF or saline solution at the time of coronary ligation (Figure 1). An almost twofold increase in capillary density was observed in the area of infarction in animals receiving the AdVEGF treatment compared with saline-injected animals $(550 \pm 80$ vs $290 \pm 70$ capillaries $/ \mathrm{mm}^{2}$, respectively, $\left.P=.001\right)$.

\section{Cell Culture and Purity}

Primary harvest of fetal cardiomyocytes yielded approximately $1 \times 10^{5}$ cells per fetal heart after expansion in culture over 7 to 10 days. Cell viability was estimated to be $95 \%$ to $99 \%$ based upon trypan blue staining of an aliquot of cells sampled just prior to cell transplantation. Approximately $80 \%$ to $90 \%$ of cultured cells were determined to be cardiomyocytes based upon a typical triangular, loosely oriented pattern of cells demonstrating spontaneous synchronized contractions (Figure 2). 


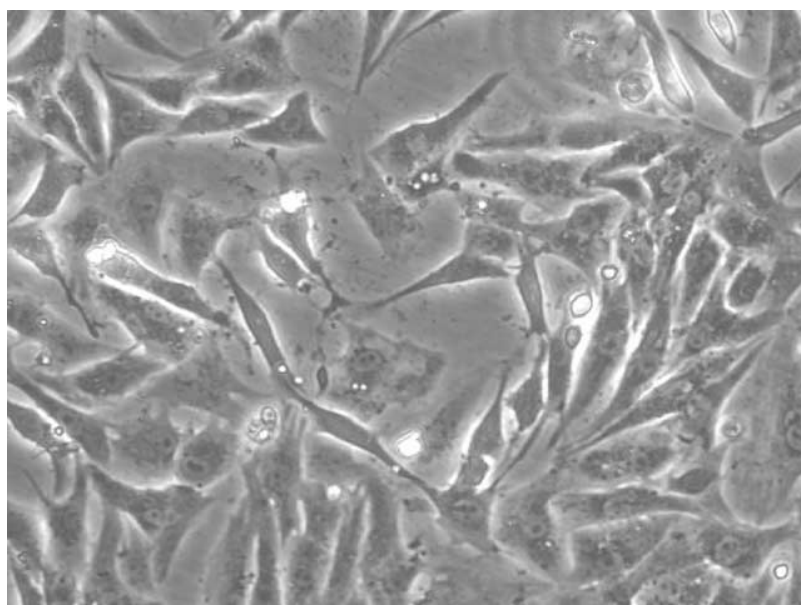

Figure 2. Photomicrographs $(200 \times)$ of cultured cells approximately 10 days after primary harvest from fetal hearts showing a typical triangular, loosely oriented pattern of fetal cardiomyocytes.

\section{Cell Implantation}

In additional preliminary experiments, myocardial sections were obtained 2 weeks after the injection of heat- or valinomycin-treated fetal cardiomyocytes that had been prelabeled with a blue fluorescent marker to verify that the detection of this marker could not be attributed to the persistent labeling of nonviable cell implants. Essentially no heat-treated cells and only sparse valinomycin-treated cells, with severely deformed and pyknotic nuclei, were detected in these sections. In contrast, more than 50 intact cells per section with normal-appearing circular nuclei were detected after implantation of an equivalent number of untreated cells into normal myocardium.

Based upon these preliminary studies, preadministration of a blue fluorescent nuclear dye was used to mark fetal cardiomyocytes prior to their implantation into areas of myocardial infarction. Areas of transmural scar into which these cells were implanted were readily identifiable by the gross morphology of hearts harvested 5 weeks after coronary ligation (Figure 3). Histologic analysis of these tissues in some cases demonstrated nearly transmural deposition of cells implanted into these tissues (Figure 4). The pattern of blue fluorescence observed in these sections was consistent morphologically with the presence of cell implants (Figure $5)$.

To quantitatively evaluate the potential ability of preadministration of angiogenic agents to enhance the survival of implanted cells, we devised a cell survival index representing the ratio of (prelabeled) blue fluorescent implanted cell nuclei divided by the number of coadministered microspheres seen in the same sections (Figure 6, A). This ratio was used to correct for variability in cell injection and sampling (Table 1). The cell survival index in sections of

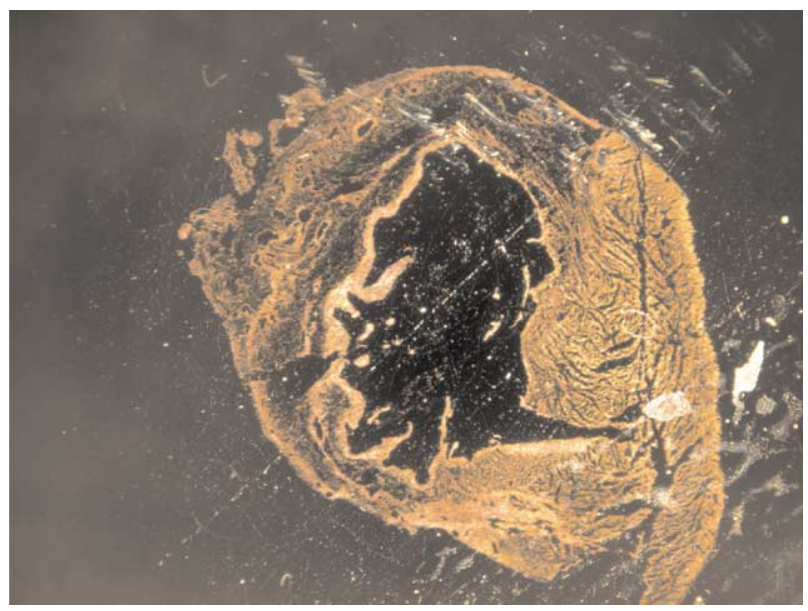

Figure 3. Gross morphology of myocardial scar and typical region of interest (circle).

infarcted myocardium obtained 2 weeks after fetal cardiomyocyte implantation and 5 weeks after VEGF, AdNull, or saline solution administration was $4.7 \pm 3.0,1.0 \pm 0.9$, and $1.9 \pm 1.4(P=.0045)$ for these groups, respectively (Figure $6, B)$.

\section{Exercise Tolerance}

Exercise tolerance was significantly prolonged in animals receiving AdVEGF 3 weeks prior to fetal cardiomyocyte implantation (at the time of coronary ligation) compared with animals receiving AdNull or saline solution at the time of coronary ligation or receiving delayed AdVEGF administration at the time of cell implantation (Figure 7; AdVEGF $[\mathrm{n}=4]$ ]: $29 \pm 4$ minutes; AdNull [n = 8]: $16 \pm 4$ minutes; saline solution $[\mathrm{n}=4]$ ]: $15 \pm 2$ minutes; "delayed" AdVEGF [n $=4$ ]: $16 \pm 1$ minutes; $P<.001)$. Animals that received saline solution alone instead of cell implantation at the time of second operation also demonstrated a shorter exercise tolerance time compared with the cell-implanted animals (AdVEGF/"no cells" [n = 3]: $17 \pm 1$ minutes; AdNull/“no cells" [n $=5$ ]: $14 \pm 2$ minutes, respectively; $P$ $<.001$ compared with AdVEGF/cells).

\section{Discussion}

Cellular cardiomyoplasty represents a novel alternative to conventional mechanical and surgical strategies for the functional enhancement of extensively infarcted myocardium. Although cellular cardiomyoplasty is already being investigated in clinical trials, ${ }^{14,15}$ much remains unknown about this new therapy. For example, although acute postinfarction inflammation has been cited as limiting cell survival following implantation, we and others have speculated that persistent ischemia in the infarct territory was another potential contributor to implanted cell loss that could consequently limit the efficacy of this therapy. ${ }^{16-18}$ Supporting 


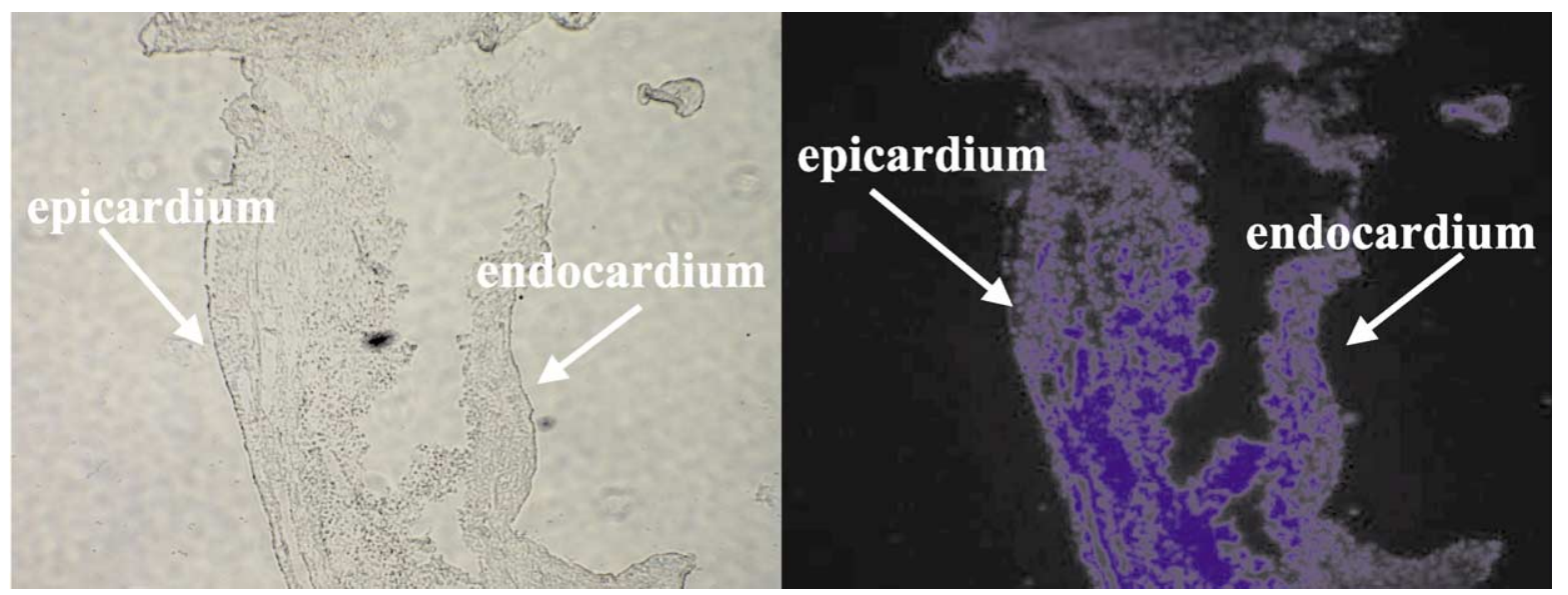

Figure 4. Photomicrographs $(40 \times)$ of area of cell administration utilizing bright field (left panel) and blue fluorescence (right panel) imaging demonstrating transmural implantation.

this hypothesis, angiogenic therapy given prior to cell implantation is demonstrated in the present study to improve: (1) vascularization of the infarct territory, (2) implanted cell survival, and (3) exercise performance.

Cellular cardiomyoplasty performed with or without the concomitant administration of angiogenic therapy has been previously reported to improve ventricular function in numerous previous postinfarct studies. ${ }^{3-13,16-18,23-26}$ The improvements in exercise performance noted in the present study suggest the potential importance of angiogenic pretreatment as an adjunct to cellular cardiomyoplasty, although differences in the efficacy parameters employed and uncertainties regarding surviving cell implant number make direct comparisons between this and prior studies difficult.

The potential importance of angiogenic pretreatment in avoiding an "ischemic interval" that may adversely affect cell survival and the consequent functional benefits of cellular cardiomyoplasty has already been noted by Sakakibara and colleagues, ${ }^{27}$ who administered basic fibroblast growth factor-incorporating microspheres 1 week prior to fetal cardiomyocyte transplantation in a rat coronary ligation model. These investigators concluded that "prevascularization" enhances the benefits of cellular cardiomyoplasty, but only relatively small improvements in ventricular function and no data in regard to cell survival were reported in this study.

In contrast to the studies of the Kyoto group, we allowed an interval of 3 weeks between the delivery of angiogenic agents and cell implantation, based upon our prior observations of the time intervals required for maximal blood vessel development following growth factor administration. ${ }^{28}$ The present data do not exclude the possibility that shorter time intervals might not adequately provide for the development of a nutritive vasculature to support cell implantation in infarcted territories. The present studies also do not exclude the potential role of the vasodilator or antiapoptotic properties of VEGF in enhancing the survival of cells implanted at these shorter intervals, although the lack of improvement noted in the "concomitant cell/AdVEGF" group in the present studies suggest that these properties are less important than "prevascularization" in enhancing the efficacy of cellular cardiomyoplasty.

Aside from the appropriate timing of angiogenic pretreatment prior to cellular cardiomyoplasty, it is interesting to speculate as to the extent of revascularization needed to maximize the results of this therapy. The approximate doubling in vascularization observed in AdVEGF versus negative control animals in the present study was consistent with a similar increase in cell survival measured in these animals. Conceivably, the observed increase in cell survival in the present study occurred as a result of a corresponding increase in perfusion of the infarcted tissues into which the cells were injected, as predicted by prior studies correlating the vascularization and perfusion of myocardial scar tissue. ${ }^{24}$ Although the dose of angiogenic vector administered in the present study was calculated, based upon prior pharmacokinetic studies, ${ }^{28,29}$ to yield a maximal angiogenic effect, it will need to be further investigated to determine whether more extensive scar revascularization would result in even better hemodynamic results following cellular cardiomyoplasty. Similarly, the role of enhanced perfusion in increasing the function of implanted cells, rather than only affecting implanted cell survival, needs to be investigated.

The potential importance of improved perfusion in enhancing the results of cellular cardiomyoplasty also does not discount the potential role of postinfarct inflammation or other stresses, such as physical strain during and after injection or cell washout through the vasculature or lymphatics, in negatively impacting net cell implantation efficiencies. ${ }^{16-18,29}$ In this regard, the therapeutic regimen utilized 

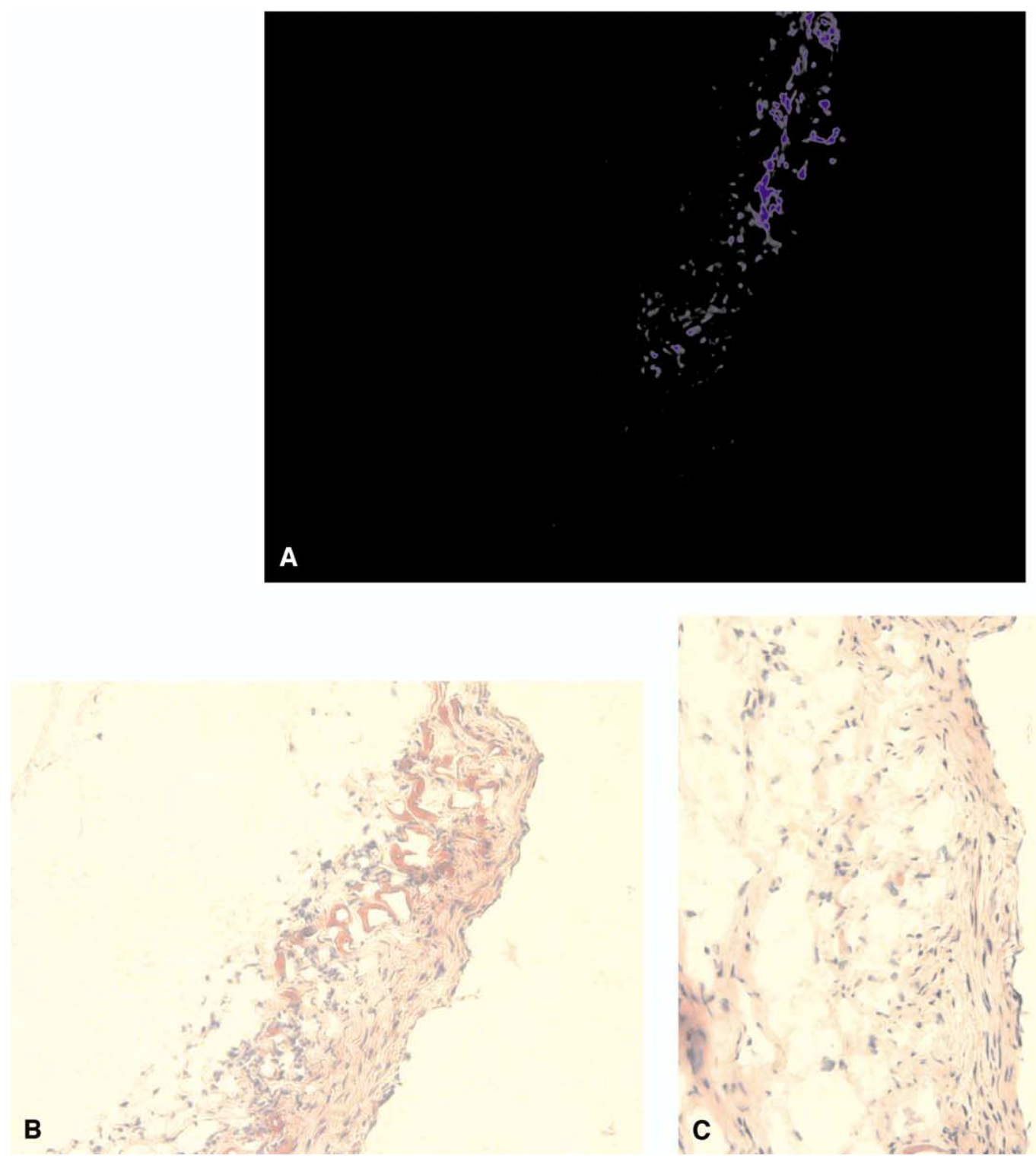

Figure 5. A, Photomicrographs $(200 \times)$ within scar region of interest depicting blue fluorescent implanted cell nuclei. B, Corresponding hematoxylin and eosin (H\&E) section. C, H\&E preparation of section that did not demonstrate blue fluorescence in corresponding sections (not shown).

in the present study was structured such that cells were implanted at a time point relatively remote from the point of coronary ligation to avoid the potentially deleterious effects of inflammation on cell survival. ${ }^{16-18}$ It is possible that cell implantation more proximate to the time of acute myocardial infarction might diminish the relevance of the current findings. On the other hand, it is likely that optimized delivery techniques could further enhance successful cell implantation.

The relatively robust, transmural repopulation of the infarct area with implanted cells achieved in this and several other studies suggest that it is possible to create an anatomic substrate sufficient to support improved ventricular hemodynamics. It is has not yet been demonstrated, however, that cells implanted into infarcted myocardium retain or develop contractile properties. Consequently, it has been suggested that the apparent efficacy of cellular cardiomyoplasty is related to the ability of cell implantation to improve the elastic or compliance properties of compromised ventricles or to prevent myocardial dilatation through the buttressing of myocardial segments thinned by infarction. ${ }^{30}$

It has alternatively been suggested that the angiogenic potential of the implanted cells, rather than the cellular substrate itself, may play an important role in the observed 

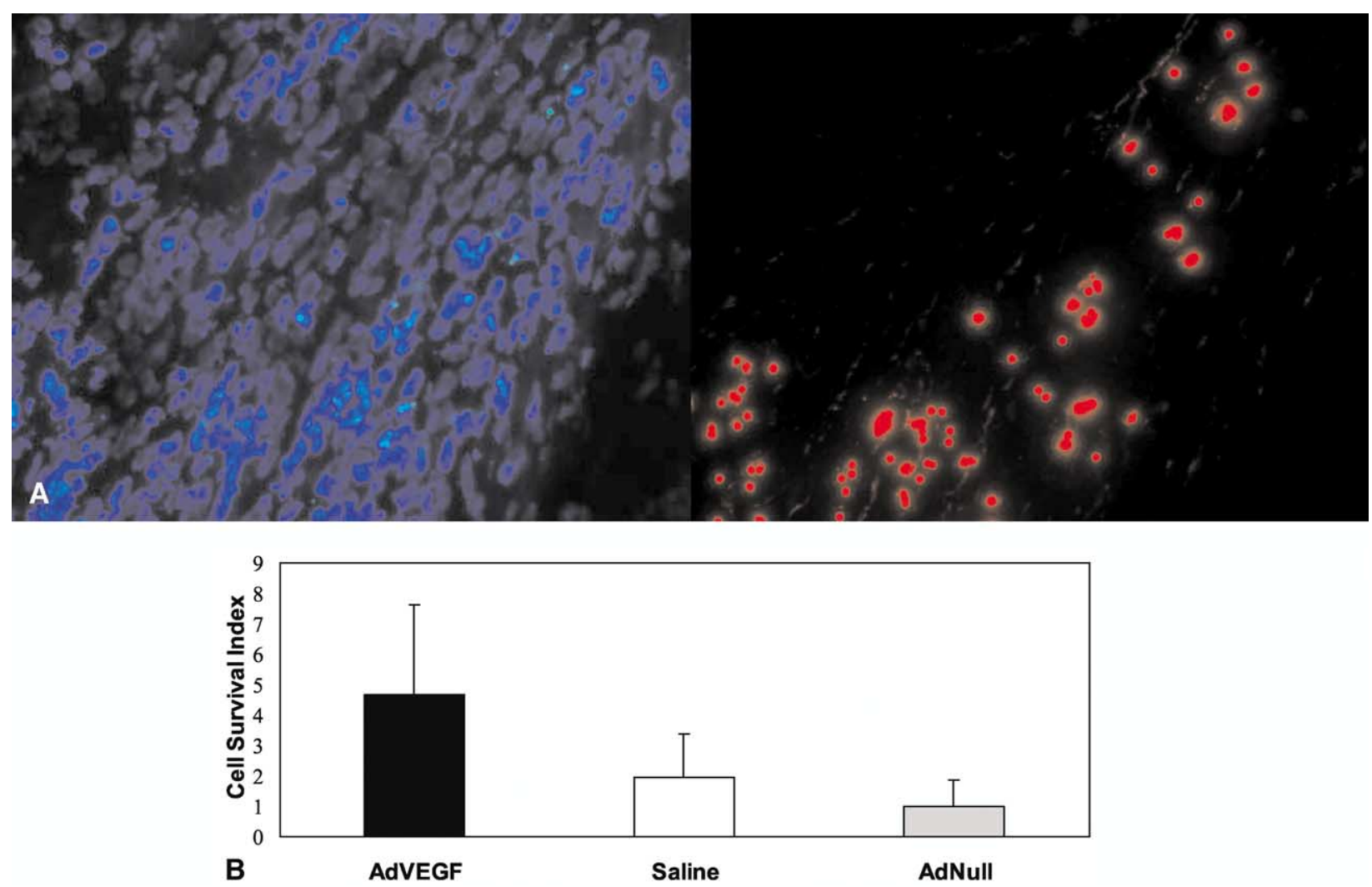

Figure 6. A, Photomicrographs $(400 \times)$ of blue fluorescent implanted cell nuclei (left panel) and red microspheres coinjected to delineate the area of cell administration (right panel). B, Cell survival index (mean \pm standard deviation) after fetal cardiomyocyte implantation and various treatments.

improvements in hemodynamics seen in cell implantation studies. ${ }^{5,23-26,30-32}$ The relative lack of benefit observed in animals receiving angiogenic treatment without cell transfer in this and other studies ${ }^{23-26}$ is not surprising given the relatively large area of infarction typical of these models, although it is interesting to note that a small but nonsignificant improvement in exercise performance was noted in the AdVEGF/"no cell" group compared with the negative control "no cell" animals. These data suggest, however, that cell implantation, rather than angiogenic therapy, is the critical therapeutic modality in improving the performance of already infarcted ventricles.

Assuming that the importance of angiogenic pretreatment in cellular cardiomyoplasty relates to improvements in cell survival, it is possible that ischemic cell loss might be overcome simply by increasing the "dose" of implanted cells. Thus, if a final dose of 1 billion cells are needed for effective cellular cardiomyoplasty, an initial dose of 100 billion cells at a $99 \%$ cell loss without angiogenic therapy might be as effective as a delivered dose of 20 billion cells with pretreatment. Such high doses, however, might challenge the efficiencies of cell culture and the limitations of volume of injection into the scar. Furthermore, it is possible
TABLE 1. Cell survival index

\begin{tabular}{lccc}
\hline & $\begin{array}{c}\text { Implanted } \\
\text { cell nuclei* }\end{array}$ & Microspherest & $\begin{array}{c}\text { Cell } \\
\text { survival } \\
\text { index }\end{array}$ \\
\hline Saline solution & $810 \pm 730$ & $390 \pm 230$ & $1.9 \pm 1.4$ \\
AdNull & $490 \pm 140$ & $540 \pm 140$ & $1.0 \pm 0.9$ \\
AdVEGF & $1550 \pm 1400$ & $330 \pm 160$ & $4.7 \pm 3.0 \S$ \\
\hline
\end{tabular}

AdNull, Empty expression cassette control vector; AdVEGF, adenovirus encoding VEGF 121.

*Total number of blue-stained nuclei detected as described in Methods. tTotal number of microspheres detected as described in Methods. $\ddagger$ Calculated as cell nuclei/microspheres as detected in Methods. $\S P=.0045$ vs other groups.

that only a finite number of cells, as compared to a percentage of injected cells, may survive in the ischemic environment of the infarcted myocardium. These considerations notwithstanding, it is important to note that the optimal cell "dose" for cellular cardiomyoplasty has not yet been determined.

There are several other limitations to the present study that need to be considered. First, although prior studies have correlated ventricular function and the exercise performance 


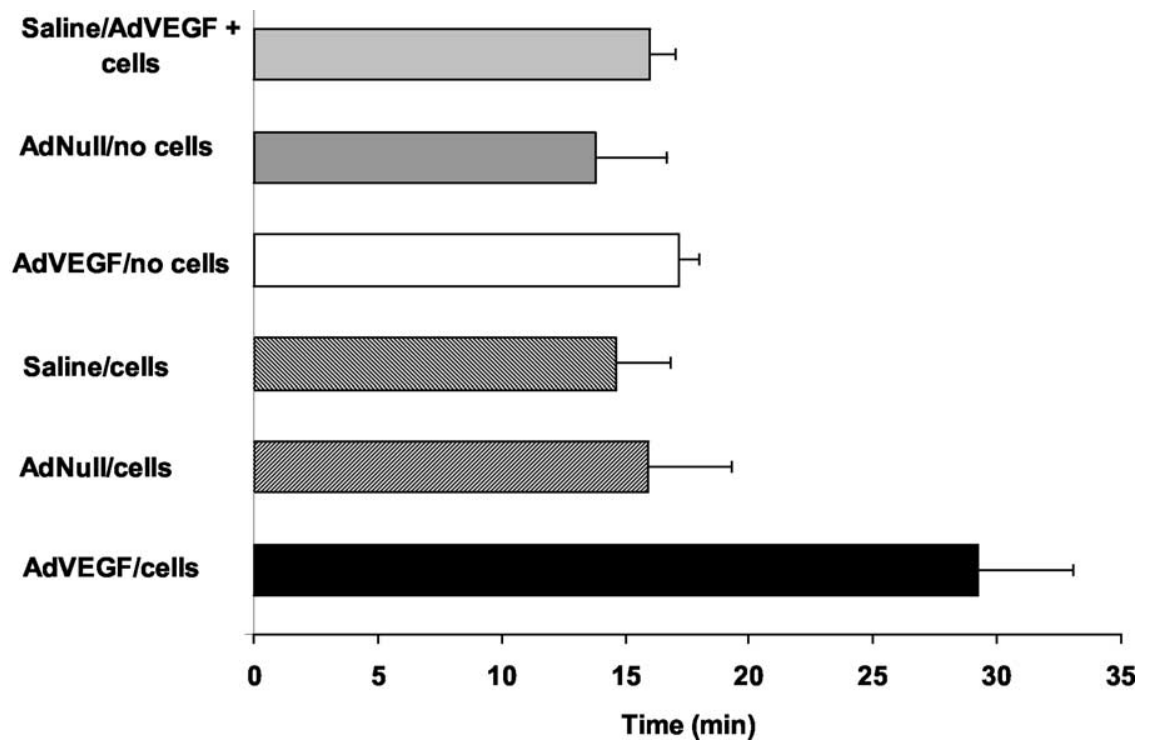

Figure 7. Exercise tolerance (mean \pm standard deviation) after various treatments with or without fetal cardiomyocyte implantation ( $P<.001$, AdVEGF/cells vs all other groups).

parameter used in this study, ${ }^{33}$ ventricular hemodynamic studies will be needed to confirm that the improvements in exercise tolerance noted in the present study are specifically attributable to changes in ventricular performance. Second, it is possible that the results of the present study are an artifact of a specific sensitivity of the fetal cardiomyocytes employed in the present study to ischemia, for which studies of cell types such as myoblasts that are potentially "hardier" than fetal cardiomyocytes are being planned. In this regard, it should be noted that the findings of the present study as yet apply only to cell implantation into areas of scar and may not be extrapolated, for example, to cell implantation into the infarct border zone, where ischemia may not play an important role in implanted cell survival. Finally, our finding of minimal benefits derived from the use of cells alone, which is inconsistent with prior work, may be a consequence of the potentially rigorous demands of the exercise performance assay utilized in these studies and/or the potential vulnerability of fetal cardiomyocytes to ischemic conditions. Planned studies utilizing different cell types and more direct ventricular function assays should also address these issues.

Although progress in the development of cellular cardiomyoplasty as a clinically relevant therapy is encouraging, many questions remain to be answered, including such issues as appropriate cell dose and cell type, mechanisms of action, and even timing of implantation. The findings of the present study provide potentially useful data regarding the importance of angiogenic pretreatment in optimizing the delivery of cellular cardiomyoplasty. Should the conclusion of the present study be proven correct, minimally invasive techniques such as catheter-based angiogenic treatments will likely be needed before such combined therapies will be clinically applicable for the treatment of acute or chronic myocardial infarction.

We thank B. Cushing for help in preparation of the manuscript.

\section{References}

1. Freedman SB, Isner JM. Therapeutic angiogenesis for coronary artery disease. Ann Intern Med. 2002;136:54-71.

2. Simons M, Bonow RO, Chronos NA, Cohen DJ, Giordano FJ, Hammond $\mathrm{K}$, et al. Clinical trials in coronary angiogenesis: issues, problems, consensus. An expert panel summary. Circulation. 2000;102: e73-86.

3. Pouzet B, Vilquin J-T, Hagege AA, Scorsin M, Messas E, Fiszman M, et al. Intramyocardial transplantation of autologous myoblasts: can tissue processing be optimized? Circulation. 2000;102(Suppl III): III210-5.

4. Jain M, DerSimonian H, Brenner DA, Ngoy S, Teller P, Edge ASB, et al. Cell therapy attenuates deleterious ventricular remodeling and improves cardiac performance after myocardial infarction. Circulation. 2001;103:1920-7.

5. Suzuki K, Brand NJ, Smolenski RT, Jayakumar J, Murtuza B. Development of a novel method for cell transplantation through the coronary artery. Circulation. 2000;102(Suppl III):III359-64.

6. Orlic D, Kajstura J, Chimenti S, Jakoniuk I, Anderson SM, Li B, et al. Bone marrow cells regenerate infarcted myocardium. Nature. 2001; 410:701-4.

7. Wang J-S, Shum-Tim D, Galipeau J, Chedrawy E, Eliopoulos N, Chiu RC-J. Marrow stromal cells for cellular cardiomyoplasty: feasibility and potential. J Thorac Cardiovasc Surg. 2000;120:999-1006.

8. Tomita S, Li R-K, Weisel RD, Mickle DAG, Kim E-J, Sakai T, et al. Autologous transplantation of bone marrow cells improves damaged heart function. Circulation. 1999;100(Suppl II):II-247-56.

9. Reinecke H, Zhang M, Bartosek T, Murry CE. Survival, integration, and differentiation of cardiomyocyte grafts: a study in normal and injured rat hearts. Circulation. 1999;100:193-202.

10. Sakai T, Li R-K, Weisel RD, Mickle DAG, Jia Z-Q, Tomita S, et al. 
Cardiothoracic transplantation. Fetal cell transplantation: a comparison of three cell types. J Thorac Cardiovasc Surg. 1999;118:715-25.

11. Atkins BZ, Lewis CW, Kraus WE, Hutcheson KA, Glower DD, Taylor DA. Intracardiac transplantation of skeletal myoblasts yields two populations of striated cells in situ. Ann Thorac Surg. 1999;67:124-9.

12. Leor J, Patterson M, QAuinones MJ, Kedes LH, Kloner RA. Transplantation of fetal myocardial tissue into the infarcted myocardium of rat. A potential method for repair of infarcted myocardium? Circulation. 1996;94(Suppl II):II332-6.

13. Klug MG, Soonpaa MH, Koh GYU, Field LJ. Genetically selected cardiomyocytes from differentiating embryonic stem cells form stable intrcardiac grafts. J Clin Invest. 1996;98:216-24.

14. Menasche P, Hagege AA, Vilquin J-T, Desnos M, Abergel E, Pouzet $\mathrm{B}$, et al. Autologous skeletal myoblast transplantation for sever postinfarction left ventrical dysfunction. J Am Coll Cardiol. 2003;41:107883.

15. Pagani FD, DerSimonian H, Zawadzka A, Wetzel K, Edge ASB, Jacoby DB, et al. Autologous skeletal myoblasts transplanted to ischemia-damaged myocardium in humans. Histological analysis of cell survival and differentiation. J Am Coll Cardiol. 2003;41:879-88.

16. Zhang M, Methot D, Poppa V, Fujio Y, Walsh K, Murry CE. Cardiomyocyte grafting for cardiac repair: graft cell death and anti-death strategies. J Mol Cell Cardiol. 2001;33:907-21.

17. Muller-Ehmsen J, Whittaker P, Kloner RA, Dow JS, Sakoda T, Long TI, et al. Survival and development of neonatal rat cardiomyocytes transplanted into adult myocardium. J Mol Cell Cardiol. 2002;34:10716.

18. Li R-K, Mickle DAG, Weisel RD, Mohabeer MK, Zhang J, Rao V, et al. Natural history of fetal rat cardiomyocytes transplanted into adult rat myocardial scar tissue. Circulation. 1997;96(Suppl II):II179-87.

19. Hersh J, Crystal RG, Bewig BB. Modulation of gene expression after replication deficient recombinant adenovirus-mediated gene transfer by the product of a second adenovirus vector. Gene Ther. 1995;2:12431.

20. Rosenfeld MA, Siegfried W, Yoshimura K, et al. In vivo transfer of the human cystic fibrosis transmembrane conductance regulator gene to the airway epithelium. Cell. 1992;68:143-55.

21. Suzuki J, Gao M, Batra S, Koyana T. Effects of treadmill training on the arteriolar and venular portions of capillary in soleus muscle of young and middle-aged rats. Acta Physiol Scand. 1997;159:113-21.

22. Bancroft JD, Gamble M. Theory and practice of histological techniques. New York: Churchill Livingstone; 2002.

23. Suzuki K, Murtuza B, Smolenski RT, Sammut IA, Suzuki N, Kaneda $\mathrm{Y}$, et al. Cell transplantation for the treatment of acute myocardial infarction using vascular endothelial growth factor-expressing skeletal myoblasts. Circulation. 2001;104(Suppl I):I207-12.

24. Yau TM, Fung K, Weisel RD, Fujii T, Mickle DAG, Li R-L. Enhanced myocardial angiogenesis by gene transfer with transplanted cells. Circulation. 2001;104(Suppl I):I218-22.

25. Miyagawa S, Sawa Y, Taketani S, Kawaguchi N, Nakamura T, Matsuura $\mathrm{N}$, et al. Myocardial regeneration therapy for heart failure hepatocyte growth factor enhances the effect of cellular cardiomyoplasty. Circulation. 2002;105:2556-61.

26. Yang Y, Min J-Y, Rana JS, Ke Q, Cai J, Chen Y, et al. VEGF enhances functional improvement of postinfarcted hearts by transplantation of ESC-differentiated cells. J Appl Physiol. 2002;93:1140-51.

27. Sakakibara Y, Nishimura K, Tambara K, Yamamoto M, Lu F, Tabata $\mathrm{Y}$, et al. Prevascularization with gelatin microspheres containing basic fibroblast growth factor enhances the benefits of cardiomyocyte transplantation. J Thorac Cardiovasc Surg. 2002;124:50-6.

28. Magovern CJ, Mack CA, Zhang J, Rosengart TK, Isom OW, Crystal RG. Regional angiogenesis induced in nonischemic tissue by an adenoviral vector expressing vascular endothelial growth factor. Hum Gene Ther. 1997;8:215-7.

29. Mack CA, Patel SR, Schwarz EA, Zanzonico P, Hahn RT, Ilercil A, et al. Biologic bypass with the use of adenovirus-mediated gene transfer of the complementary deoxyribonucleic acid for vascular endothelial growth factor 121 improves myocardial perfusion and function in the ischemic porcine heart. J Thorac Cardiovasc Surg. 1998;115:168-77.

30. Muller-Ehmsen J, Peterson KL, Kedes L, Whittaker P, Dow JS, Long TI, et al. Rebuilding a damaged heart long-term survival of trans- planted neonatal rat cardiomyocytes after myocardial infarction and effect on cardiac function. Circulation. 2002;105:1720-6.

31. Taylor DA, Atkins BZ, Hungspreugs P, Jones TR, Reedy MC, Hutcheson KA, et al. Regenerating functional myocardium: improved performance after skeletal myoblast transplantation. Nat Med. 1998; 4:929-33.

32. Kamihata H, Matsubara H, Nishiue T, Fujiyama S, Tsutsumi Y, Ozono $\mathrm{R}$, et al. Implantation of bone marrow mononuclear cells into ischemic myocardium enhances collateral perfusion and regional function via side supply of angioblasts, angiogenic ligands, and cytokines. Circulation. 2001;104:1046-52.

33. Barbato JC, Lee SJ, Koch LG, Cicila GT. Myocardial function in rat genetic models of low and high aerobic running capacity. Am J Physiol Regul Integr Comp Physiol. 2002;282:R721-6.

\section{Discussion}

Dr Richard Weisel (Toronto, Ontario, Canada). Dr Rosengart, I would like to ask what you believe would be the appropriate indication for your combined cell and gene therapy. Your previous work on angiogenic gene therapy was aimed at patients who have jeopardized but viable myocardium. Cell transplantation has been reserved for patients who have a completed infarction without viable myocardium at risk. Patients with an extensive infarction with thinning and dilatation are probably candidates for ventricular restoration rather than cell or gene therapy. Therefore, angiogenic pretreatment may be adequate treatment for patients who have viable myocardium. Angiogenic pretreatment in patients with no viable myocardium may improve cell survival and enhance the benefit associated with cell transplantation. What are your thoughts on the spectrum of patients who will require treatment?

I wanted to ask you about what indications you see for this combined therapy. The work that you had previously done demonstrated very nicely that angiogenic therapy is probably very beneficial for those people who cannot undergo the classic revascularization strategies but have viable myocardium that is jeopardized. Cell transplant as we indicated has been used for those people who have no viability that you can demonstrate on any test in a region that you also can't revascularize. Of course the limitation with that, as we suggested, was that if the area is already thinned and dilated you probably should whack it out rather than putting cells into it, so now you are putting the 2 together. You are obviously crossing the boundaries, which is likely where our treatment is, because we seldom know for sure whether the patients have adequate viability or not after they have had an infarction. Particularly if they don't have an aneurysm, then they probably have viable muscle, so where do you see the treatments of angiogenic therapy, cell therapy, or the combination working into that situation? Obviously if you already had some vascularity, you wouldn't need angiogenic therapy, but the majority of patients don't have adequate revascularization so some of them could be done with just angiogenic therapy, some with a combination, and some may need to have a biodegradable patch put in rather than cell therapy. What are your thoughts on this spectrum that we need to treat?

Dr Rosengart. Thank you, Dr Weisel. I would think that areas that are completely infarcted and that can't be resected would certainly be appropriate for cell transplant. If there is a significant amount of ischemia, and eventually we may be able to develop an appropriate index for that, we may have to pretreat with angiogenic therapy. I think it will be interesting to see with additional studies whether or not you really need to pretreat in all cases as opposed 
to administering cells, untransfected with angiogenic agents. Theoretically, you would expect that by the time transplanted angiogenic cells can induce a blood supply they would have already been subjected to the risk for necrosis, so pretreatment is potentially appealing in terms of improving cell survival. I think there will probably be a spectrum wherein most patients will get a combination. I think that the patients with purely ischemic disease would just get angiogenic therapy, either as gene or protein therapy or potentially cells as these appear to be angiogenic as well. Patients who are on the other end of the spectrum with large infarctions are going to need cell transplant with or without angiogenic pretreatment, and certainly some of this will be performed via catheter-based technique.
Unidentified speaker. Todd, I have a quick question. How did you arrive at the 3-week interval? Is that empiric?

Dr Rosengart. That is really based on a number of our initial studies where it would appear at least in our hands that induced neovascularization plateaus at about 3 weeks. There is at least 1 other study looking at this concept reported by Professor Komeda of the Kyoto group where pretreatment was performed 1 week pre-implant. This study did show some benefit and it will be interesting to see if this holds true, whether there is an ideal time to wait and whether 1 week is adequate, or whether it would be appropriate to wait for 3 weeks between angiogenic therapy and all.

Thank you. 